\title{
Intervention to Prevent Mental III-Health Among Health Care Workers
}

I Hans Michélsen'

Associate Professor, Department of Neurobiology, Care Sciences and Society, Karolinska Institutet, Sweden

I Ulla Sebrant

PhD, Senior Lecturer, Department of Education, Uppsala University, Sweden

I Abbe Schulman

MD, PhD, Senior Lecturer, Department of Neurobiology, Care Sciences and Society, Karolinska Institutet, Sweden

\begin{abstract}
Psychological strain in working life is gaining ever more attention. Health care workers are often under extreme emotional stress, which can become so overwhelming that they show signs of mental ill-health.

This project aimed to develop a model for sustainable psychological support within a hospital clinic to prevent mental ill-health among employees.

Mental strains at work and mental ill-health among clinic employees were mapped out, after which interventions for psychological support were designed in collaboration with employees. The interventions were conducted over one year and evaluated. Throughout the process the clinic received continuous feedback. Both questionnaires and interviews were used.

The results of identifying mental strains and conducting interventions showed that employees experienced mental strain at work and perceived a need for support. Intervention evaluations showed that the project provided support, new insights, and an increased acceptance for long-term prevention of mental strain. Quantitative and qualitative methodologies supported the results.

The conclusion was that increased legitimacy for mental strain at work and continuous feedback between clinic management and employees, as well as organizational circumstances are important factors when developing long-term intervention programs with various forms of psychological support.
\end{abstract}

\section{KEY WORDS}

Health care workers / longitudinal research / mental strain / preventive program / psychological support

\section{Introduction}

he tasks, organization, and management of work, as well as the social and environmental contexts of work can influence an employee's mental and physical health in various ways (Cox et al., 2000). The ways these various factors of work interact and influence the employee have been summarized in models such as the Demand-Control

\footnotetext{
${ }^{1}$ E-mail: hans.michelsen@ki.se
} 
Model (Karasek and Theorell, 1990) and the Effort-Reward Imbalance Model (Siegrist, 1996). In a meta-analysis of many empirical studies based on these models, there was consistent support for the finding that a combination of high demands, low-decision latitude, and low rewards in the psychosocial work environment creates risk factors for the development of mental disorders (Stansfeld and Candy, 2006). The Job DemandsResources Model (Bakker et al., 2004) emphasizes how the conditions at work can affect the employees' health both negatively and positively. Demands at work are not necessarily always negative, and may also contribute to employees' growth, learning, and development (Bakker and Demerouti, 2007). Subjective well-being as a type of health outcome has also been studied in relation to work environment factors. Stansfeld et al. (2013) have shown that psychosocial work environment factors and personal social support have significance when it comes to well-being.

In health care, employees are constantly engaging in personal interactions with people in need of medical attention and care. "The available scientific evidence suggests that those who work in the healthcare setting, especially with direct contact with and responsibility for patients and other people, may be particularly at risk from the experience of work-related stress" (Cox et al., 2002, p. 3). Mental strain in health care is characterized by high demands on one's competence and ability to relate to and empathize with the patient's problem, combined with the demand for professional objectivity. Furthermore, these demands must be fulfilled in a work environment characterized by tight time pressure and a situational-driven work process that changes according to patients' different needs (Firth-Cozens and Payne, 1999; Peterson, 2003; Su et al., 2009). Psychological strains, often a combination of several different strains, may in some cases be overwhelming for health care employees, leading to short-term or long-term signs of mental ill-health, which may even lead to sickness absenteeism (Gillespie and Melby, 2003; Michie and Williams, 2003; Rugulies et al., 2007).

Within the health care industry, structural changes, financial cutbacks, and extensive reorganizations (Borrill and Parker, 2000; Waris, 1999) have been made based on strictly financial reasoning, with expectations for improved quality and shortened time spent under care. Organizations have made cutbacks, merged, and shifted focus, which means that employees' social networks and social support have been disrupted, work duties have changed, employment has become less secure, and personnel turnover is high (Harvey et al., 2003; Mackie et al., 2001). The nature of one's occupation, together with its place in the organizational hierarchy, could play an indirect role in the production of distress, considering the fact that different professions/occupations operate under different conditions and experience different types of strains (Marchand et al., 2005). The professions relevant in this study within a hospital clinic are doctors, midwives, nurses, and other health care personnel such as licensed practical nurses and medical assistants. Health care in Sweden is currently characterized by a high level of complexity as the traditional hierarchy among professional groups is undergoing changes. New forms of collaboration are necessary among employees, especially in the health care professions. These structural factors have increased the strains, stress, and mental ill-health among employees (Davidson et al., 1997).

Furthermore, organizational management and personnel support structures appear to be of great importance for employees' mental health. Job security and preventive health care promote employees' good health, which in turn contributes to the improved functioning of the organization (Waris, 1999). Organizational structures such as staffing functions 
and other personnel policies apparently have a direct impact on the work environment (Buttigieg et al., 2011; Cooper and Cartwright, 2004; Hyde et al., 2009). Accordingly, local managers ought to receive support from the organization (by upper management), since they have a key role in facilitating the creation of a positive and collaborative work environment between professional groups and the role of distributing responsibility in teams (VanVactor, 2012). Hall et al. (2013) mean that the development of a robust psychosocial supportive climate in general can have a buffering effect for psychosocial risks at workplaces. Moreover, British researchers have established a connection between treatment results and various work environments, showing that patient death rates decreased when an organization went from being centralized to team based (West et al., 2002).

Personnel support activities in health care organizations have been directed both toward strengthening the individual's ability to cope with strains at work and to reduce existing strains within the organization (Hawkins and Shohet, 2000). According to Burke and Richardsen (2000), both attempts may be difficult to systematically evaluate and are often based on field studies. Nonetheless, many intervention studies have been conducted to reduce occupational stress within health care. In order to study the effectiveness of such studies, researchers including Ruotsalainen et al. (2008) conducted a thorough systematic review of the interventions that had been done. Using strict quality controls of the studied interventions, the authors (op. cit.) found a total of 14 randomized controlled trials, 3 cluster-randomized trials, and 2 crossover trials. They reached the following conclusion: "Limited evidence is available for a small, but probably relevant reduction in stress levels from person-directed, person-work interface, and organizational interventions among health care workers" (Ruotsalainen et al., 2008, p. 169). In parallel with the project-initiated interventions, there are often continuous changes underway within the organization-changes that could either support or counteract the intended effects of interventions. Cox et al. (2007) point out that studies of interventions adapted to the workplace as a way of processing mental strains have many inherent methodological challenges, since the design of the study must be adapted to the existing organizational situation. Furthermore, they think that the study design should reflect both the intervention process and results, and also utilize both quantitative and qualitative data.

The research referenced in this study shows how stress and mental ill-health emerge and manifest in the workplace as well as the need for interventions to prevent mental ill-health at work. Our overarching purpose has been to both identify and examine how such problems can be managed and prevented. We used a case-study approach in a women's clinic within a larger hospital that was interested in participating in the project.

\section{Aim}

The aim was to develop a model for psychological support for employees in acute health care, with the following subpurposes:

to map out existing mental strains and mental ill-health within various professions and units at one hospital clinic;

to design and employ, together with management and employees, psychological support initiatives tailored to each workplace; 
to evaluate the effects of psychological initiatives and possible changes in mental strain and mental ill-health within the different professions at the clinic.

Thus, the project intended to illuminate the following research questions: Which mental strains did various professional groups report based on their work experience with patients and their families? Which mental strains did they report based on their experience of the internal cooperation among various professional groups? Which types of psychological support had personnel expressed a need for? Finally, what are the effects of a support program developed in collaboration with the clinic management?

\section{Materials and method}

The study used a longitudinal design, including quantitative and qualitative data, spanning 3.5 years with an analysis of mental strain and mental ill-health of all employees at one hospital clinic. Initially, the interview data collected concerned mental strain at work and the perceived need for personnel support interventions. Thereafter, personnel support interventions were conducted and concluded with repeated data collection on mental strain and mental ill-health. Changes in mental strain and mental ill-health were tracked using questionnaire surveys done before and after the interventions and interview data were collected in order to describe employees' experiences of the interventions.

The project was organized into a structure that could manage the ongoing progress reports and coordinate the researchers, clinic management, and the local unions. The project's structure also provided a forum for continuous contact with the consultants who were responsible for implementing the support initiatives. The purpose was to give the initiatives a common framework within the clinic in order to reduce the risk that they would be isolated activities within their particular departments. The experiences from the project were also regularly reported back to the involved personnel and department managers. Before the data collection began, the line managers and head doctors at each department within the clinic were informed of the project and were also interviewed about the mental strains they believed existed in the work of their departments. This project organization formed the basis for the following: the development of a model of psychological support based on inventories of mental strains, the development of psychological support adapted to the unique needs of each department, and the implementation of support measures followed by evaluations and feedback to managers and employees.

On the one hand, conducting the project at an individual clinic has certain limitations when it comes to being able to generalize the results. On the other hand, the study design offered broad access to various types of data that allowed for deeper knowledge of the organization and its work groups and employees in relation to the mental strains and types of support available in their work. This kind of knowledge is valuable primarily for understanding the conditions in other clinics, but can even be applied to workplaces outside the health care system. Since one purpose of the study was to operate in close cooperation with the clinic's various departments and to develop support initiatives for the personnel based on an analysis of what each department considered to be mentally straining, the case-study method was a natural choice. Another starting point 
for the project was to study departments that had different types of work tasks, in order to reflect different types of mental strain.

\section{Participants}

The project was conducted at a women's clinic within a larger hospital in Stockholm. At the time of the first and second surveys, 373 and 422 people, respectively, were on staff (anyone on leave of absence, on long-term sick leave, or paid by the hour was not included). The clinic was organized into nine separate units and a single administrative team consisting of doctors from each unit. The project's interventions were conducted at five of these units and in a part of the administrative team of doctors. The selection was supported by the fact that the units represented various types of medical care: prenatal and postnatal care, diagnostics, surgery, and gynecology care unit. The other four units, which were largely parallel units to those involved in the intervention program, as well as parts of the doctor's group, were used as a control group. Comparisons between those who participated and those who did not participate in interventions were conducted for various professions, doctors, midwives, nurses, nurse assistants, and administrative personnel. No comparisons between the units were done as agreed upon by the clinic management. Those types of comparisons could lead to a situation where individuals, most likely unit managers and doctors, could be identified in the results.

\section{Data collection}

The data collection started with exploratory interviews in single-profession groups. The groups were composed by the line managers. The interviews, which were recorded, focused on three themes: what the employees experienced as mentally strenuous situations at work, whether there was access to psychological support at work, and which type of psychological support employees felt they needed access to. The interviews were used in order to develop the interventions initiated by the project.

Ten months prior to the interventions, and three months after their conclusion, a questionnaire was issued to all participating employees (373 and 422 people, respectively). The questionnaire consisted of three parts: (a) background questions: age, sex, civil status, profession, number of years in profession; (b) mental strain and work situation were studied with six indices where all questions had 4 answer alternatives. The indices were: mental strains (five questions such as "Does your work require you to do things very quickly?"), stimulation at work (four questions such as "Do you learn new things in your work?") and control over one's work (two questions such as "Are you able to decide how your work tasks should be done?”) (Karasek and Theorell, 1990), social support at work (five questions such as "Are you appreciated by your colleagues in your work?") (Undén and Orth-Gomér, 1989), social climate at work (six questions such as "At work, colleagues are helpful and supportive), (Theorell, 2000), and an index regarding pride of profession (four questions such as "Do you feel that your work is meaningful?") (Michélsen and Bildt, 2003); (c) mental health was studied with General health questionnaire (GHQ 12), containing 12 questions and 4 answer alternatives scored 0 to 3 . The higher the score, the more distressed the respondent. Responses 
were dichotomized in accordance with Goldberg and Williams (1988), whereby ratings of 0 or 1 are coded as " 0 " and ratings 2 or 3 as " 1 ," giving a range of 0 to 12 . Degree of burnout consisted of 22 questions divided into three indices: emotional exhaustion (EE), depersonalization (DP), and reduced personal performance (PA) (Maslach and Jackson, 1986), for which every question had seven answer alternatives.

The data collection ended with structured interviews conducted individually or in groups, with the participants in the interventions and their line managers, in order to evaluate the project's interventions. The interviews were recorded and addressed the following themes: motivation, organizational support, group climate, confidence in the consultant, whether or not the intervention had offered psychological support, whether or not it had offered opportunities for relief and processing one's own experiences, and whether the organization had become better at acknowledging and legitimizing the need to discuss issues concerning mental strains in the work.

\section{Data analysis}

After being transcribed, interview data were processed with qualitative methods (Denzin and Lincoln, 1994). In the issue-orienting group interviews, testimonies regarding perceived mental strain at work, experiences in how these strains have been handled, as well as wishes for psychological support were grouped into narrative themes for each profession in the selected units. The interpretation of the material led to a differentiated picture of how employees, based on their function and position, reasoned about mental strain at work and its consequences.

The evaluation interviews were collected and interpreted with regard to how the participants experienced the various interventions. Both interviewers conducted their own interpretations, after which a double processing was combined into one final version per interview.

The questionnaire material was assembled descriptively. Mean values from the six work-related indices from the two surveys were compared using a $t$-test, broken down by profession. Outcome data (impaired mental health, at risk of burnout) were dichotomized and data for those who participated were compared with data for those who did not participate in the interventions, for the entire clinic broken down by profession.

The relationship between background variables, variables for work situation, and the four outcome measurements (GHQ 12, three indices for burnout) was examined. The regression models for each outcome included the variables "participated" or "did not participate," significant background and workplace environment variables, and the outcome from both surveys including the interaction between surveys. Only those who answered both questionnaires have been included in these analyses. Relationships to each outcome measurement were analyzed with logistic regression for repeated measurements according to a generalized linear model with the PROC GENMOD data program SAS (1989). The distribution assumption for GHQ 12 sum of symptoms (0-12) was a negative binomial distribution, corresponding to the index for burnout of a binomial distribution. During the statistical modeling, the distribution assumptions were checked and also the model's discrimination values.

Information, oral and written, to all participants regarding participation in the study and handling of data has adhered to the ethical demands for research instituted by 
the Swedish Research Council (www.vr.se). Results from the study are reported in such a way that no individual person can be identified.

\section{Results}

\section{Exploratory interviews}

In the exploratory interviews mental strains were found to be somewhat different for different professions, and certain differences were related to the different type of care provided in each unit. The following situations were described as mentally strenuous:

Heavy workload. Having many tasks and a high tempo at work were perceived to be mentally strenuous situations by everyone. Doctors, midwives, and nurses in particular stressed factors such as the complexity of the tasks and the high demands for competence. A high work tempo reduced the opportunities to learn and discuss new things at work. Tight schedules gave no opportunity to consider one's own scheduling and planning. Difficulties in upholding boundaries between work and private lives were very common due to close involvement with the patients, and feelings of inadequacy.

Difficult work situations and special patients. Especially difficult or unexpected crisis-like situations in health care, such as when a child dies during birth or negative events during surgery, constituted extreme strains. Many felt feelings of guilt and inadequacy and worried about being involved in such situations. Doctors, midwives, and nurses expressed fear of making a mistake and worried about being reported to the malpractice council. Certain patients and cases, such as rape, miscarriage, abortion, difficult cancer cases, and also simply long-term contact with patients, roused strong feelings in employees. There were also direct threats made against the personnel and their families.

Ethical dilemmas. Within the gynecology unit there were ethical dilemmas that arose in relation to patients who wanted an abortion. Despite the fact that abortion is legal in Sweden, personnel felt a great ambivalence about being involved. Doctors in training were especially exposed since they were largely responsible for receiving abortion patients. Both doctors and health care personnel were almost entirely women, which meant that there was a great likelihood for identifying with the patient's situation. Midwives and doctors, who worked with ultrasound examinations of pregnant women, often experienced much uncertainty and anxiety in the event they should discover a deformed fetus and have to relay this news to the pregnant woman and her family.

Organizational factors. Considerable structural changes and financial cutbacks in health care caused uncertainty for all employees as well as resulting in understaffing and a lack of resources. Recurring management changes on all levels created uncertainty. Doctors, midwives, and nurses were constantly worried about not being able to do their jobs in accordance with the ethical guidelines dictated by their professions. Line managers, midwives, and nurses felt worried about making mistakes in the financial reporting they were required to do. Delegation of leadership within the clinic was a sensitive issue. The doctors felt that their authority was being called into question since the formal leadership on the unit level had been shifted to midwives and nurses, respectively, and changes in the work routines meant that each profession's assisting function in relation to each other was removed, resulting in situations of stressful uncertainty and frustration between 
the professions. The shift to digital information and the dependence on computers was another strenuous organizational factor for many.

\section{Interventions}

Identified mental strains at work were reported back to the organization, after which seven interventions were developed in cooperation with line managers and employees. The reported mental strains for each department were compiled to form a content base for the interventions. All interventions recognized and acknowledged mental strain at work, and devoted some time to personal development. Two interventions $(1+2$ in Table 1$)$ focused on organizational circumstances and changes, while others were more focused on relational issues and individual support. The exact form of each intervention was also adapted to each department's preferences regarding group members and meeting times over the course of the year that the intervention would take place. Each intervention was led by a qualified consultant. Separate contracts were drawn up to specify the focus of each intervention, the relationship between the intervention consultant, the clinic, and the project leaders, as well as requirements for confidentiality. The seven interventions are summarized in Table 1 and include the number of participants and conducted interviews of each concluded intervention.

\section{Parallel events within the clinic}

One year after the start of the project, the clinic restructured its organization and went from being a flat organization in which all units were directly responsible to the head of operations, to a matrix organization, including certain unit changes. The clinic's care mandate was also expanded somewhat. These types of changes were done at many hospitals in Sweden during the time of the study and had no connection to this project. In similarity to the conditions at many other hospital clinics in Stockholm at this time, there was also a high personnel turnover. During the course of the project, one-third of the personnel were replaced.

\section{Evaluation of the interventions}

Two types of evaluations are presented: a qualitative element done through interviews with those who participated (61 individual and 3 group interviews) and a quantitative element that compares the questionnaire results before and after the interventions.

\section{Interview results}

Intervention 1. The participants worked with several specific organizational problems within the unit regarding the conflict between the demands of the outside world and what the employees considered to be the fundamental responsibility of their health care unit. All participants felt that the group's work resulted in an increased awareness of the 
Table I Interventions

\begin{tabular}{|c|c|c|c|c|}
\hline \multirow[t]{2}{*}{ Problems addressed } & \multirow[t]{2}{*}{ Focus of intervention } & \multirow[t]{2}{*}{ Participants } & \multicolumn{2}{|c|}{ Number of participants } \\
\hline & & & Intervention & Interview \\
\hline \multirow[t]{2}{*}{$\begin{array}{l}\text { Mental strain in con- } \\
\text { nection with organiza- } \\
\text { tional issues, work du- } \\
\text { ties, and responsibility }\end{array}$} & $\begin{array}{l}\text { Intervention I } \\
\text { Organizational goals, work } \\
\text { duties, and participation }\end{array}$ & $\begin{array}{l}\text { Representatives } \\
\text { from all professions } \\
\text { (4 midwives, I unit } \\
\text { doctor, I nurse's aide, } \\
\text { I secretary) and one } \\
\text { unit manager in a } \\
\text { health care unit }\end{array}$ & 7 & 7 \\
\hline & $\begin{array}{l}\text { Intervention } 2 \\
\text { The division of work } \\
\text { duties, cooperation, } \\
\text { responsibility issues, and } \\
\text { opportunities for personal } \\
\text { development at work }\end{array}$ & $\begin{array}{l}\text { All surgery nurses } \\
\text { and nurse assistants } \\
\text { within a surgery unit, } \\
\text { divided into two } \\
\text { groups of mixed } \\
\text { professions }\end{array}$ & 17 & 11 \\
\hline \multirow[t]{2}{*}{$\begin{array}{l}\text { Mental strain at work, } \\
\text { and how to develop } \\
\text { peer support }\end{array}$} & $\begin{array}{l}\text { Intervention } 3 \\
\text { Tested a modified format } \\
\text { of the annual personal } \\
\text { development discussions } \\
\text { for personnel in two health } \\
\text { care units }\end{array}$ & $\begin{array}{l}\text { Discussions between } \\
\text { the line manager and } \\
\text { the employee in one } \\
\text { health care unit }\end{array}$ & 27 & 20 \\
\hline & $\begin{array}{l}\text { Intervention } 4 \\
\text { Practice "reflection" to } \\
\text { review and discuss the } \\
\text { mentally strenuous situ- } \\
\text { ations of the day before } \\
\text { going home }\end{array}$ & $\begin{array}{l}\text { Entire staff of an ob- } \\
\text { stetrics department }\end{array}$ & 49 & 6 \\
\hline \multirow{3}{*}{$\begin{array}{l}\text { Psychologically difficult } \\
\text { situations at work }\end{array}$} & $\begin{array}{l}\frac{\text { Intervention } 5}{\text { Difficult situations regard- }} \\
\text { ing patients and their } \\
\text { relatives }\end{array}$ & Assistant physicians & 10 & 7 \\
\hline & $\begin{array}{l}\frac{\text { Intervention } 6}{\text { Difficult ethical dilem- }} \\
\text { mas during contact with } \\
\text { patients }\end{array}$ & $\begin{array}{l}\text { A group of } 6 \text { mid- } \\
\text { wives and } 2 \text { doctors } \\
\text { at a diagnostic unit }\end{array}$ & 8 & 8 \\
\hline & $\begin{array}{l}\frac{\text { Intervention } 7}{\text { Difficult situations in rela- }} \\
\text { tion to patients and their } \\
\text { relatives, and in the rela- } \\
\text { tionships between nurses } \\
\text { and nurses' aides }\end{array}$ & $\begin{array}{l}\text { Two mixed-profes- } \\
\text { sion groups consist- } \\
\text { ing of nurses and } \\
\text { nurse assistants at a } \\
\text { gynecology care unit }\end{array}$ & 22 & 14 \\
\hline
\end{tabular}

organization, increased influence over decisions, as well as a chance to practice taking a more critical approach. The multidisciplinary group gave the members more knowledge about each others' work conditions and facilitated collaboration. The experiences of this intervention inspired the group to continue working on its own in a similar way. 
They saw that this group was strategic for the unit's work, an opinion shared by the unit management.

Intervention 2. The communication within the unit and between the unit management and personnel was a central theme for the groups in the surgery unit. Taking responsibility and articulating one's own efforts and personal development potential emerged as an important challenge. The surgery personnel felt that participation in the group brought increased emotional and social support and also provided relief and opportunities for processing mental strains. They saw a greater openness and mutual respect develop within the group, and wanted to continue the guidance as a form of support for an ongoing open dialogue within the unit.

Intervention 3. The annual personal development meeting, between the manager and employee, was expanded with questions concerning perceived mental strain at work. All employees had experienced different types of mental strains during the year and also had a need to discuss them. Just over half of those interviewed had addressed mental strain during the personal development meeting with their manager. The meeting was considered a good forum for addressing mental strain at work, but there was also a need to talk about strenuous events as they occurred. There were suggestions made for two personal development meetings per year with the manager, one concerning education and personal development and another concerning each employee's mental strain and mental health.

Intervention 4. The development and implementation of the "reflection" method within a health care unit, in order to acknowledge the issue of mental strain and create a forum for daily relief was focused on a framework and structure for reflection. They worked to gain long-term support for the method within the entire personnel group. However, this was inhibited by the large personnel turnover and the very different needs of the midwives versus other health care personnel. The midwives were involved in developing the method, while the other health care personnel felt that the issues raised there did not concern them. Midwives stated that reflection provided relief in the work and that they had learned how the method could be used. Reflection had given them support for putting sensitive issues and difficult work-related subjects into words.

Intervention 5. During the planning it became clear that the need for psychological support varied among doctors depending on their different positions and levels of responsibility. The guidance that was done was directed only to assistant physicians. The theme in guided intervention was the assistant physicians' level of exposure in difficult patient cases, in cooperation with other professions and with superiors. The assistant physicians were in a specific situation where they were short-term employees undergoing training and also the least experienced among the doctors. The guided intervention had functioned as a relief and the participants received support in discussing difficult experiences, which they experienced as emotional support. The assistant physicians insisted that the guidance should be a natural part of the work. The management for the doctors pointed out the need for psychological support to doctors in general and that the completed guidance had a positive effect.

Intervention 6. This intervention concerned support in psychologically difficult situations for a special unit for diagnostics with midwives and doctors. The focus in this group was ethical considerations, responsibility, and relaying difficult news to patients, questions that became relevant in the diagnostic work. The guidance had given the participants emotional and social support. They experienced that the guidance brought relief and that they could process difficult experiences. Solidarity within the group and 
between the professions was strengthened with greater understanding for each other's work. The group and unit management agreed that the guidance had been a very positive experience and that continued guidance would be very important for providing security and relief at work.

Intervention 7. This intervention involved support in psychologically difficult situations for all personnel, divided into two groups of mixed professions, both nurses and nurse assistants, at a gynecological care unit. The guidance process primarily addressed approaches and feelings surrounding difficult patient situations, but also some organizational issues. The guidance had created an increased openness and greater preparedness to talk about one's feelings. Participants experienced this as a relief in connection with difficult patient situations. They saw that there was a need for continuous guidance and support.

\section{Questionnaire results before and after the interventions}

The answer frequency for the first survey was 283 respondents, or $76 \%$, and 271 respondents, or $64 \%$ for the other. The nonresponse was proportionally large in all professional groups.

Personnel turnover was another kind of nonresponse. Of those who answered the first survey, $29 \%$ had quit by the second survey and $38 \%$ of the respondents in survey two were newly employed since the first survey. During the project time the personnel turnover was greatest among midwives and nurse assistants. The distributions of answers for a number of variables were similar within each profession for those who quit and for those who were still working. A deviation applied to other health care personnel where those who quit had higher mental strains and a larger proportion reported a sense of diminished mental well-being. New employees in all professional groups had median age of 10 years less than those who had worked at the clinic throughout the entire project period, and their professional experience was somewhat shorter. A greater proportion of new employees reported a sense of diminished mental well-being compared to those who had worked at the clinic longer.

\section{Exposure}

The work environment was studied using six indices (Table 2). One significant change from the first to the second survey was that perceived mental strains in the work had diminished for doctors $(\mathrm{p}<.05)$ and for midwives $(\mathrm{p}<.001)$. A significant worsening of the opportunities to influence decisions $(\mathrm{p}<.01)$ was apparent among the other health care personnel. Among nurses there was a significant decline in the social climate at work $(\mathrm{p}<.001)$. Other comparisons between the first and second measurements showed no significant changes.

\section{Outcome}

During the first survey one fourth of all employees reported some signs of diminished mental well-being according to the General Health Questionnaire (GHQ 12, cut-off >2) 
Table II Mean values and standard deviations on six indices measuring how work-related factors were perceived on two occasions ( $\mathrm{TI}$ and $\mathrm{T} 2$ ) by five categories of professionals

\begin{tabular}{|c|c|c|c|c|c|c|}
\hline Category & 'Mental strain & ${ }^{2}$ Stimulation & $\begin{array}{l}{ }^{3} \text { Involvement } \\
\text { in decisions }\end{array}$ & $\begin{array}{l}{ }^{4} \text { Social working } \\
\text { climate }\end{array}$ & $\begin{array}{l}{ }^{5} \text { Support on } \\
\text { the job }\end{array}$ & $\begin{array}{l}{ }^{6} \text { Pride of } \\
\text { profession }\end{array}$ \\
\hline \multirow{2}{*}{$\begin{array}{l}\text { MDTI } \\
n=38 \\
T 2\end{array}$} & $\begin{array}{l}\text { Mean SD } \\
16.62 .4\end{array}$ & $\begin{array}{l}\text { Mean SD } \\
\mid 3.0 \text { |.5 }\end{array}$ & $\begin{array}{l}\text { Mean SD } \\
5.11 .6\end{array}$ & $\begin{array}{l}\text { Mean SD } \\
2.90 .5\end{array}$ & $\begin{array}{l}\text { Mean SD } \\
2.70 .5\end{array}$ & $\begin{array}{l}\text { Mean SD } \\
3.30 .4\end{array}$ \\
\hline & $15.3 * 2.1$ & 12.91 .7 & $5.6 \quad 1.4$ & 3.00 .5 & 2.60 .5 & 3.30 .5 \\
\hline $\begin{array}{l}M w T \mid \\
n=133\end{array}$ & 15.72 .9 & $\mid 2.51 .4$ & 6.01 .3 & 3.20 .4 & 2.70 .5 & 3.40 .4 \\
\hline $\mathrm{T} 2$ & $14.6 * * * 2.5$ & $|2.5| .5$ & 6.01 .3 & 3.20 .4 & 2.80 .5 & 3.40 .4 \\
\hline $\begin{array}{l}\text { NuTI } \\
n=33\end{array}$ & | 4.22 .8 & $\mid 2.31 .6$ & 5.21 .4 & 3.30 .5 & 2.80 .5 & 3.30 .4 \\
\hline $\mathrm{T} 2$ & I5.4 2.0 & 12.41 .2 & 5.11 .4 & $2.8 * * * * 0.3$ & 2.70 .6 & 3.30 .4 \\
\hline $\begin{array}{l}\text { OCTI } \\
n=60\end{array}$ & | 4.83 .1 & 11.21 .9 & 5.41 .6 & 3.10 .6 & 2.60 .6 & 3.20 .5 \\
\hline $\mathrm{T} 2$ & | 4.82 .4 & $1 \mid .51 .7$ & $4.7 * * * 1.6$ & 3.00 .4 & 2.60 .5 & 3.30 .4 \\
\hline $\begin{array}{l}\text { Adm TI } \\
n=16\end{array}$ & I2.5 3.1 & 12.02 .3 & 6.41 .7 & 3.30 .4 & 2.90 .6 & 3.20 .8 \\
\hline $\mathrm{T} 2$ & | 3.32 .6 & 12.51 .7 & 6.21 .4 & 3.10 .7 & 2.90 .6 & 3.30 .4 \\
\hline
\end{tabular}

$M D=$ Doctor; $M w=$ Midwife; $\mathrm{Nu}=$ Nurse; $\mathrm{OC}=$ Other caregiver, $\mathrm{Adm}=$ Administrative staff.

Notes. Higher scores reflect more demanding work tasks, more stimulation, greater influence on decisions, better working climate, more social support, and greater pride of profession.

'5-20 points; ${ }^{24-16}$ points; ${ }^{32} 2-8$ points; ${ }^{4-6} \mid-4$ points.

*Decreased $p<.05$ between the first and the second survey.

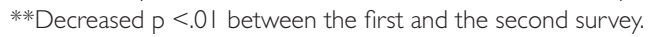

*****areased $p<.001$ between the first and the second survey.

(Goldberg and Williams, 1988). However, the clinic's personnel, divided by profession, did not differ from corresponding professions in a representative population sample regarding GHQ 12 within Stockholm County at the same point in time. The proportion of those with diminished mental well-being fell somewhat during the second survey for the entire clinic, regardless of whether employees had participated in the interventions. Although the same pattern applied to doctors and midwives, the tendency was reversed for both nurses and other caregivers who had participated in the interventions (Table 3). No change was significant. No results in the outcome variables were reported for administrative personnel since only one person participated in any intervention and can thus be identified.

The risk for burnout at work was studied using Maslach's instrument (Maslach and Jackson, 1986), with cut-off limits according to Jeanneau and Armelius (2000). 
Table III Percent with impaired mental health (according to GHQ 12) or at risk of burnout (according to three Maslach indices) on two occasions ( $\mathrm{TI}$ and $\mathrm{T} 2$ ) within the entire clinic and broken down into four categories of professionals

\begin{tabular}{|c|c|c|c|c|c|c|c|c|c|}
\hline \multicolumn{2}{|c|}{$\begin{array}{l}\text { Category } \\
\text { Participated in } \\
\text { intervention } \\
\text { Occasions } \\
\mathrm{TI} \text { and T2 }\end{array}$} & $\begin{array}{l}\mathrm{GHC} \\
\text { yes }\end{array}$ & no & $\begin{array}{l}E E> \\
\text { yes }\end{array}$ & no & $\begin{array}{l}\text { DP> } \\
\text { yes }\end{array}$ & no & $\begin{array}{l}\mathrm{PA}< \\
\text { yes }\end{array}$ & no \\
\hline $\begin{array}{l}\text { Entire } \\
\text { clinic }\end{array}$ & $\begin{array}{l}\text { T1 } \\
\text { T2 }\end{array}$ & $\begin{array}{l}18 \\
17\end{array}$ & $\begin{array}{l}24 \\
22\end{array}$ & $\begin{array}{l}36 \\
31\end{array}$ & $\begin{array}{l}34 \\
21\end{array}$ & $\begin{array}{l}21 \\
36\end{array}$ & $\begin{array}{l}26 \\
16\end{array}$ & $\begin{array}{l}15 \\
9\end{array}$ & $\begin{array}{l}17 \\
18\end{array}$ \\
\hline$M D$ & $\begin{array}{l}\mathrm{T} 1 \\
\mathrm{~T} 2\end{array}$ & $\begin{array}{l}17 \\
10\end{array}$ & $\begin{array}{l}32 \\
17\end{array}$ & $\begin{array}{l}67 \\
20\end{array}$ & $\begin{array}{l}29 \\
23\end{array}$ & $\begin{array}{l}33 \\
50\end{array}$ & $\begin{array}{l}52 \\
33\end{array}$ & $\begin{array}{l}0 \\
10\end{array}$ & $\begin{array}{l}19 \\
17\end{array}$ \\
\hline$M w$ & $\begin{array}{l}\mathrm{T} 1 \\
\mathrm{~T} 2\end{array}$ & $\begin{array}{l}25 \\
17\end{array}$ & $\begin{array}{l}26 \\
23\end{array}$ & $\begin{array}{l}30 \\
27\end{array}$ & $\begin{array}{l}41 \\
19\end{array}$ & $\begin{array}{l}25 \\
40\end{array}$ & $\begin{array}{l}28 \\
14\end{array}$ & $\begin{array}{l}15 \\
10\end{array}$ & $\begin{array}{l}12 \\
13\end{array}$ \\
\hline $\mathrm{Nu}$ & $\begin{array}{l}\text { T1 } \\
\text { T2 }\end{array}$ & $\begin{array}{l}0 \\
13 \\
9\end{array}$ & 12 & $\begin{array}{l}40 \\
50\end{array}$ & $\begin{array}{l}20 \\
36\end{array}$ & $\begin{array}{l}20 \\
25\end{array}$ & $\begin{array}{l}24 \\
18\end{array}$ & $\begin{array}{l}20 \\
0\end{array}$ & $\begin{array}{l}20 \\
36\end{array}$ \\
\hline$O C$ & $\begin{array}{l}\mathrm{T} 1 \\
\mathrm{~T} 2\end{array}$ & $\begin{array}{l}14 \\
27\end{array}$ & $\begin{array}{l}23 \\
23\end{array}$ & $\begin{array}{l}29 \\
40\end{array}$ & $\begin{array}{l}32 \\
26\end{array}$ & $\begin{array}{l}0 \\
27\end{array}$ & $\begin{array}{l}9 \\
7\end{array}$ & $\begin{array}{l}14 \\
7\end{array}$ & $\begin{array}{l}25 \\
21\end{array}$ \\
\hline
\end{tabular}

$M D=D o c t o r ; M w=M i d w i f e ; ~ N u=N u r s e ; O C=O t h e r$ caregiver.

$\mathrm{EE}=$ emotional exhaustion, $\mathrm{DP}=$ depersonalization, $\mathrm{PA}=$ diminished personal accomplishment.

*cut-off for impaired mental health as defined for the GHQ 12 method (Goldberg and Williams, 1988).

***cut-off for risk of burnout according to Jeanneau and Armelius (2000).

Within the entire clinic, the proportion who reported risk for EE fell. When viewed by profession, the same was true for doctors and midwives, regardless of whether or not they participated in the interventions, but the risk increased for nurses and nurses' aides who participated in the interventions. Across all professions, the proportion that reported risk for DP was greater among those who participated in the interventions than for those who did not participate. Regarding the index "diminished personal accomplishment (PA)" the proportion of those reporting risk diminished for three professions but increased for doctors.

Change in mental health between the two surveys, for both participants and nonparticipants in the project's interventions, was studied using a regression analysis model for ordinal data (PROC GENMOD, SAS, 1989). As a measure of mental health the sum of symptoms (0-12) in GHQ 12 was used. The regression analysis showed no significant changes over time (Table 4) although there was a tendency for those who had participated $(\mathrm{p}=.11)$ and those who had not participated $(\mathrm{p}=.07)$ to have lower values for GHQ 12 during the second measurement. However, descriptively, we found that the proportion of people with a sum of symptoms 0 (high degree of mental well-being) during the first survey was larger in the group that participated in the interventions 
compared to those who did not participate. In other words, there were less conducive conditions for positively influencing mental health in the group that participated in the interventions.

In the regression analysis it was also evident that a generally significant $(\mathrm{p}<.001)$ connection between professional pride and GHQ 12 existed, where higher professional pride was related to a lower sum of symptoms. Significant $(\mathrm{p}<.001)$ connections also emerged with a lower assumed sum of symptoms for those who were living together compared to those who were not.

In a regression analysis for EE there was no significant assumed change over time, either for participants or nonparticipants in interventions (Table 4). Significant relations emerged where increased mental strains resulted in a somewhat higher value of EE $(\mathrm{p}<.001)$, living together resulted in lower values of EE compared to not living together $(\mathrm{p}=.02)$, and higher values for EE for those with children at home compared to those without children at home $(\mathrm{p}=.02)$. The regression analysis regarding DP showed a significant $(\mathrm{p}=.02)$ estimated change over time with a lower DP for the first survey compared to the second for those who participated (Table 4). Those who did not participate in interventions had only a marginally higher DP in the first survey compared to the second survey. Furthermore, there was a significant relation between increased mental strains and increased DP $(\mathrm{p}=.04)$.

In the regression analysis regarding the index reduced PA no significant changes emerged over time with regard to participation and nonparticipation in interventions. However, the analysis did show a significant relation with professional pride $(\mathrm{p}<.001)$, where greater professional pride resulted in greater estimated PA.

Table IV Odds ratio for change TI/T2 in GHQ 12 and three indices for burnout, emotional exhaustion (EE), depersonalization (DP), and reduced personal performance (PA)

\begin{tabular}{|c|c|c|c|}
\hline & OR 95\% & $\mathrm{Cl}$ & $\mathrm{p}$-value \\
\hline \multicolumn{4}{|l|}{ General Health Questionnaire } \\
\hline Participated in intervention & 2.1 & $0.8-5.2$ & 0.11 \\
\hline Not participated & 1.6 & $1.0-2.8$ & 0.07 \\
\hline \multicolumn{4}{|l|}{ Emotional exhaustion } \\
\hline Participated in intervention & 1.0 & $0.9-1.2$ & 0.71 \\
\hline Not participated & 1.1 & $1.0-1.2$ & 0.19 \\
\hline \multicolumn{4}{|l|}{ Depersonalization } \\
\hline Participated in intervention & 0.7 & $0.5-0.9$ & 0.02 \\
\hline Not participated & I.I & $0.9-1.4$ & 0.43 \\
\hline \multicolumn{4}{|l|}{ Reduced personal performance } \\
\hline Participated in intervention & I.। & $0.8-1.4$ & 0.55 \\
\hline Not participated & 1.0 & $0.9-1.1$ & 0.78 \\
\hline
\end{tabular}

All models adjusted for living situation, professional pride, six work-related variables, and participated or not participated in intervention 


\section{Discussion}

The main results of this study show that there is a need for psychological support and measures to prevent mental ill-health at work. The employees encountered multiple and burdensome mental strains in their health care work even if the strain profile varied somewhat depending on profession and the type of care offered by the clinic. Between the project's two measurement points, the mental strain of work for two professional groups-doctors and midwives-showed a general reduction, while the opportunity to influence decisions seemed to decrease somewhat for other health care personnel. For nurses, the social climate appeared to be worsened. These differences can partly be explained by the organizational changes that occurred within the clinic during the course of the project. The changes brought a clearer division of work tasks, responsibilities, and management functions, particularly for doctors and midwives. Other health care personnel (nurses, nurse aides) showed tendencies toward increased mental strain, which may possibly be attributable to the fact that these groups were not the focus of the clinic's organizational changes. These professional groups may have felt that their situations worsened or stagnated.

An aspect of the study results that may be seen as somewhat contradictory is the change in the outcome variable DP where the proportion who risked DP increased among those who participated in the interventions compared to those who did not participate. Possibly, participation in the interventions may have helped employees recognize and define their experiences of contradictory and stressful work conditions. The evaluation interviews provide a certain basis for this interpretation, since the participants have become more aware of others' experiences of strains at work. In the other burnout indices-EE and PA-certain tendencies to changes emerged, although they were not significant. The positive change in mental health (GHQ 12) was estimated to be somewhat stronger for those who participated in interventions even if the estimations were not significant. However, data from the first survey showed that there was a larger proportion of employees who reported good mental well-being, or 0 in GHQ 12, among those who participated in the project's interventions compared to those who did not participate. This group could thus not improve its mental health for the second survey after having participated in interventions. Among the professional groups who participated in interventions, there was a positive change primarily for midwives, and a somewhat negative change among nurses and other caregivers. Possibly, the organizational changes meant that midwives could also benefit more from participating in the project's interventions. Considering the short length of the intervention program and the organizational changes during the same time, the results are of great interest. These results also share similarities with other hospital studies (Cox et al., 2002).

The main interview results from the intervention participants and their managers drew a qualitative image of the importance of the interventions, which had brought psychological support and relief especially with regard to direct interaction with patients. The organizational-focused interventions resulted in a new awareness of the opportunities for influencing decisions and taking responsibility in the organization, similar to the results from the participative work conference presented by Mattila et al. (2006). Participants had gained a greater understanding of the work duties of their colleagues, which in turn had the potential to minimize conflict between professions and create a foundation for a more open and constructive cooperation. Some interventions focused 
on supporting the participants' own competence, learning and development in their professional roles, which contributed to strengthening their professional identity. The results of the interviews also showed that attitudes and relationships within the clinic had become more open, and that there was a greater legitimacy for acknowledging mental strain and mental well-being/ill-health. One conclusion of the evaluation interviews was that continuous preventive efforts consisting of different forms of personnel support would be necessary in order to protect employees from mental ill-health, as well as support for their professional development and learning.

Strains and challenges in professional life can be acknowledged and handled both by the individual and through organizational and interpersonal measures. The interventions in this project were designed within the existing organization, with a focus on interpersonal support in various work groups; two of the interventions $(1+2$, Table 1$)$ also had an organizational perspective. Each of the interventions was designed in response to the wishes of the work group, with the intention of creating a shared sense of participation for the support initiatives.

The results showed that it became legitimate for personnel to articulate the various types of strains in their work, and to express the need for psychological support. An approach that incorporates participation and influence in the design of psychological support within the workplace can create a foundation for a more supportive and secure work climate in the long run, where psychological support is a natural part of working, and also that it can be developed as needed.

The project's working method for developing and implementing personnel support into the organization may be summarized in an intervention model for preventive efforts, regarding mental strain and mental ill-health at work (Figure 1).

Figure I: A sustainable intervention process.

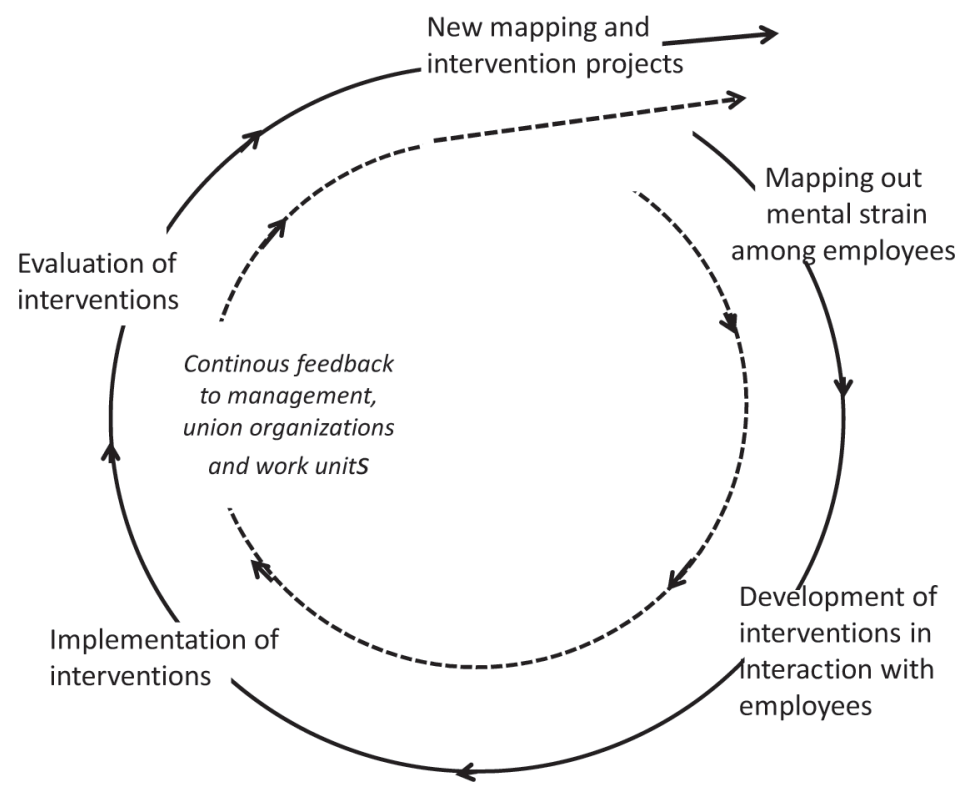


The model contains four parts: mapping out mental strains, developing interventions, implementation, and evaluation of the interventions. The model is built on reciprocity, with a continuous stream of feedback to the clinic management, the union organizations, and the hospital units during each phase of the process, and the employees should be involved in developing the interventions. For sustainable development, the model can be seen as a continuous process. Once the project has gone full-circle and an evaluation has been completed, a new process can begin to map out perceptions and issues to assess the current situation once more. The model has some similarities with the "risk management process" described by Cox et al. (2000) but with a focus on mental strain and mental ill-health. The employees' subjective experiences of mental strain at work-strain that may be related to organizational conditions, work-duty conditions, or relational circumstances-have served as the foundation for developing the interventions.

Continuous feedback within the project's intervention model was established as a process and was used to convey information about the planning, follow-through, and evaluation of each individual intervention. This interactive process created the conditions for shifting the responsibility of psychological support for employees from various department initiatives to a coordinated effort run by the clinic management, which can be viewed as an important step toward a more long-term and sustainable form of personnel support.

These results relate well to the basic views and empirical results surrounding the application of the Job Demands-Resources model, according to Bakker and Demerouti (2007). The authors (op. cit.) point out the importance of recognizing both the strains and the resources in the work, and that these are specific for different types of professions. In order to reflect different professions in a more nuanced way, Bakker and Demerouti (2007) also recommend a two-step model for mapping out the conditions within the organization. First, a qualitative phase is conducted via interviews of both the employees and their managers to define the various strains and conditions in different professions. This is then followed by a survey with both workplace-specific questions and general estimation scales to describe strains and measures of health. This approach is similar to the one used in our study, which allowed us to introduce, after the initial analysis, workplace-specific interventions that were later evaluated.

The work done within our project has also similarities with the recent research that Dollard and McTernan presented in "Psychosocial safety climate" (2011) where interventions in the organization-some of which are directed toward the organization itself and the individuals within, and some of which are only directed at individuals-can complement each other in the creation of a more secure and supportive work environment. According to Dollard and McTernan's perspective, the intervention model used in this project could be supplemented with even more organizational measures.

Developing personnel support is a long-term endeavor that requires motivation and participation from both managers and employees in a mutually responsive communication process. Clear organizational leadership in this area creates ownership and responsibility for personnel support. Participation in the process was intended to create motivation among the employees. For all interventions there were examples of improved knowledge sharing and understanding of the mental strains involved in work-both within and between the different professions. Applying the model for introducing interventions may help prevent issues concerning psychological support from becoming peripheral and to reduce the risk that individual personnel support projects end up only as temporary actions. 
The project organization team had an invaluable role in coordinating interventions throughout the course of the project. Obstacles to implementing the necessary personnelsupport initiatives, or for being able to plan such initiatives in the long term, can be traced to organizational structures such as the hierarchal traditions that have created a kind of territorial thinking on the part of the profession (Sebrant, 2008). The resistance on a personal and professional level against being aware of one's own weaknesses and needs for support was apparent in the project in many ways. Mental ill-health may be felt as something far too private to discuss in a work group, and many believe that mental strain at work is a natural part of one's professional role. Therefore, it is necessary that there is a legitimacy in the workplace for acknowledging mental strain (Obholzer and Roberts, 1994). Support for such legitimacy was developed during the project's issue mapping phase. During this phase, the focus was on allowing employees to put into words, define, and reflect on exactly which parts of the duties were mentally strenuous. This legitimacy can be developed by gradually uncovering what employees experience as mentally straining at work. However, in a turbulent health care organization, maintaining a focus on personnelsupport measures has proven to be very complicated. Personnel needs are often given a lower priority - a mechanism that is regularly recurring within health care (Cox et al., 2000).

The basis for these general experiences of the developed intervention model has been taken from the interviews done and the efforts made to shape and conduct the interventions. A more in-depth picture of the intervention model requires its continued use so that defining the various steps in the process, designing interventions, and evaluating them can be repeated two or more times as in the circular model. In this respect, the length of the project was too short.

\section{Methodological considerations}

A methodological strength of the project was the longitudinal strategy to collect quantitative and qualitative data both before and some time after the interventions were concluded. However, following an organization over a period of time can also make it difficult to adapt project design to the existing circumstances and parallel processes within the organization. Contents and meaning of parallel processes within the clinic during the course of the project, in the form of organizational changes, have not been examined in more depth in this study, even if it is reasonable that the changes would primarily have an effect on the work environment indices that were used. The explorative interviews that were used to create an inventory of mental strains among employees and the subsequent interviews used to evaluate the interventions did not gather specific material about parallel processes within the clinic. This type of information would be of great value for evaluating the conducted interventions, and it would also be a meaningful complement to the developed intervention model as a part of the feedback process outlined above.

The tailored interventions, adapted for existing needs within each department, may be more difficult to evaluate with regard to content using the more general outcome variables such as GHQ 12 and burnout index in this project. The theme-focused evaluation interviews have served to illuminate the value of a legitimacy of being able to more clearly recognize mental strain and mental ill-health, as well as a more open attitude 
within the clinic and an increased understanding of other professional groups and their work conditions. The combination of various data collection techniques has proven to be valuable-it is a way of working advocated by researchers including Mimura and Griffiths (2003), and which is in line with Cox et al.'s (2007) call for a broader view of evaluations of organization-specific interventions. It would have also been valuable to supplement the evaluation of the intervention model with certain organizational data such as sickness absenteeism, personnel turnover and financial figures-information that Lamontagne et al. (2007) expressed a need for in their review of evaluations of job-stress interventions.

The follow-up time for the project's interventions may have been too short-approximately three months after the interventions were concluded. It was possible to do comparisons between the two measurement points for the entire clinic and for each professional group, but comparisons between departments could not be done due to the ethical considerations where individuals must remain unidentifiable.

One methodological problem was that employees could not be chosen randomly for participation or nonparticipation in the different interventions, which were tailored for selected units. Another limitation in the study was nonresponse. However, nonresponse was proportionally equal in all professions. Like many other hospitals in the country during the time of the study, the studied clinic had considerable personnel turnover, which meant that many did not participate in both surveys. However, those who quit after the first survey largely answered in a similar way to those who remained. Analyses of change have been done only with data from the employees who participated in both surveys.

\section{Conclusions}

The conclusions we can draw from the project are that mental strain continuously occurs in hospital work, and that the mental stress of this constant occurrence can be met with a clear and coordinated strategy comprised of different need-centered forms of psychological support.

The applied intervention model, which was implemented at a large hospital clinic, and which enabled regular feedback between employees and management, was based on a collected inventory of mental strains and the subsequent design, execution, and evaluation of focused psychological support measures. The experiences from the project showed that there must be a legitimacy and willingness of the organization's leadership, managers, and other employees to recognize and acknowledge the existence of mental strains at work, and the fact that these strains can vary between different departments as do the needs for psychological support. Such differences may also enrich the development of different types of support in a coordinated intervention model.

Interventions with participants from different professions enable increased awareness of the mental strains others encounter in their work, and encourage interprofessional collaboration. The intervention model with continuous feedback and support for the different steps in the project proved to be very powerful for building shared knowledge of mental strains caused by work at the clinic.

Both quantitative and qualitative data were necessary to evaluate the intervention models, in terms of both general changes in mental strains and mental health, as well 
as specific experiences from various forms of psychological support. These data must be framed in an organizational perspective and supplemented with organizational data such as sickness absenteeism, personnel turnover, and financial variables in order to provide a solid foundation for a sustainable system of psychological support within the organization.

An additional aspect of developing an intervention model involves tracking and evaluating how the management processes each intervention and uses experiences from completed interventions as a way to continue developing the organization's psychological support system. Such efforts were not possible during this particular study since the intervention coordinators assumed, to some degree, the role of the management during the interventions.

Additional research is greatly needed in order to obtain more in-depth knowledge of the long-term effects of intervention models which are tailored to the organization and which focus on psychological support within health care, especially in cases where the management assumes an active role in the intervention efforts.

\section{References}

Bakker, A. B., Demerouti, E. and Verbeke, W. (2004), "Using the Job Demands-Resources model to predict burnout and performance", Human Resource Management, 43(1): 83-104.

Bakker, A. D. and Demerouti, E. (2007), "The Job Demands-Resources model: state of the art”, Journal of Managerial Psychology, 22(2): 309-328.

Borrill, C. and Parker, Sh. (2000), "Change Management and Stress", in Flood, P., Dromgoole, T., Carroll, S. and Gorman, L. (Eds) Managing strategy implementation. An organizational behaviour perspective. Oxford: Blackwell Publishers, pp. 80-95.

Burke, R. J. and Richardsen, A. M. (2000), “Organizational-level interventions designed to reduce occupational stressors”, in Dewe, P. and Leiter, M. (Eds) Coping, health and organizations. London: Taylor \& Francis, pp. 191-212.

Buttigieg, S. C., West, M. A. and Dawson, J. F. (2011), "Well-structured teams and the buffering of hospital employees from stress", Health Services Management Research, 24: 203-212.

Cooper, C. L. and Cartwright, S. (2004), "Organizational management of stress and destructive emotions at work", in Payne, R.L. and Cooper, C.L. (Eds) Emotions at work, theory, research and applications for management. Chichester: John Wiley \& Sons Ltd, pp. 269-280.

Cox, T., Griffiths, A. and Rial-González, E. (2000), Research on work-related stress. Office for Official Publications of the European Communities, European Agency for Safety and Health at Work, Luxembourg.

Cox, T., Randall, R. and Griffiths, A. (2002), Interventions to control stress at work in hospital staff. Institute of Work, Health \& Organizations, University of Nottingham, Research report 435/2002, Nottingham.

Cox, T., Karanika, M., Griffiths, A. and Houdmont, J. (2007), "Evaluating organizational-level work stress interventions: beyond traditional methods", Work \& Stress, 21(4): 348-362.

Davidson, H., Folcarelli, P. H., Crawford, S., Duprat, L. J. and Clifford, J. C. (1997), “The effects of health care reforms on job satisfaction and voluntary turnover among hospitalbased nurses", Medical Care, 35(6): 634-645. 
Denzin, N. and Lincoln, Y. (Eds.) (1994), Handbook of qualitative research, London: Sage.

Dollard, M .F. and McTernan, W. (2011), "Psychosocial safety climate: a multilevel theory of work stress in the health and community service sector", Epidemiology and Psychiatric Sciences, 20(4): 287-293.

Firth-Cozens, J. and Payne, R. L. (Eds.) (1999), Stress in health professionals: psychological and organisational causes and interventions, Chichester: John Wiley \& Sons.

Gillespie, N.A. and Melby, V. (2003), "Burnout among nursing staffing accident and emergency acute medicine: a comparative study", Journal of Clinical Nursing, 12(6): 842-851.

Goldberg, D. P. and Williams, P. (1988), A user's guide to the General Health Questionnaire, Berkshire, UK: NFER-NELSON Publishing Company,.

Hall, G. B., Dollard, M. F., Winefield, A. H., Dormann, C. and Bakker, A. B. (2013), "Psychosocial safety climate buffers effects of job demands on depression and positive organizational behaviours", Anxiety, Stress \& Coping, 26(4): 355-377.

Harvey, S., Kelloway, K. and Duncan-Leiper, L. (2003), "Trust in management as a buffer of the relations between overload and strain", Journal of Occupational Health Psychology, 8(45): 306-315.

Hawkins, P. and Shohet, R. (2000), Supervision in the helping professions, Buckingham, UK: Open University Press.

Hyde, P., Harris, C., Boaden, R. and Cortvriend, P. (2009), "Human relations management, expectations and healthcare: a qualitative study", Human Relations, 62(5): 701-725.

Jeanneau, M. and Armelius, K. (2000), “Self-image and burnout in psychiatric staff”, Journal of Psychiatric and Mental Health Nursing, 7(5): 399-406.

Karasek, R.A. and Theorell, T. (1990), Healthy work: stress, productivity and the reconstruction of working life, New York: Basic Books.

Lamontagne, A. D., Keegel, T., Louie, A. M., Ostry, A. and Landsbergis, P.A. (2007), “A systematic review of the job-stress intervention evaluation literature, 1990-2005", International Journal of Occupational and Environmental Health, 13: 268-280.

Mackie, K. S., Holahan, C. K. and Gottlieb, N. H. (2001), "Employee involvement management practices, work stress, and depression in employees of a human services care facility", Human Relations, 54(8): 1065-1092.

Marchand, A., Demers, A. and Durand, P. (2005), "Does work really cause distress? The contribution of occupational structure and work organization to the experience of psychological distress", Social Science \& Medicine, 61: 1-14.

Maslach, C. and Jackson, S. E. (1986), Maslach Burnout Inventory. Manual, Palo Alto, LA: Consulting Psychologists Press.

Mattila, P., Elo, A.-L., Kuosma, E. and Kylä-Setälä, E. (2006), "Effect of a participative work conference on psychosocial work environment and well-being", European Journal of Work and Organizational Psychology, 15(4): 459-476.

Michélsen, H. and Bildt, C. (2003), "Psychosocial conditions on and off the job and psychological ill health: depressive symptoms, impaired psychological wellbeing, heavy consumption of alcohol", Occupational and Environmental Medicine, 60(7): 489-496.

Michie, S. and Williams, S. (2003), "Reducing work related psychological ill health and sickness absence: a systematic literature review", Occupational and Environmental Medicine, 60(1): 3-9.

Mimura, C. and Griffiths, P. (2003), “The effectiveness of current approaches to workplace stress management in the nursing profession: an evidence based literature review", Occupational and Environmental Medicine, 60(1): 10-15.

Obholzer, A. and Roberts, V. Z. (Eds.) (1994), The unconscious at work, London: Routledge. Peterson, C. (2003), "Stress among health care workers", Journal of Occupational Health Safety, 19(1): 49-58. 
Rugulies, R., Christensen, K. B., Borritz, M., Villadsen, E., Bultmann, U. and Kristensen, T.S. (2007), "The contribution of the psychosocial work environment to sickness absence in human service workers: results of a 3-year follow-up study”, Work \& Stress, 21(4): 293-311.

Ruotsalainen, J., Serra, C., Marine, A. and Verbeek, J. (2008), "Systematic review of interventions for reducing occupational stress in health care workers", Scandinavian Journal of Work, Environment \& Health, 34(3): 169-178.

SAS II. (1989) SAS/STAT user's guide version $6,4^{\text {th }}$ edn. SAS Institute Inc, Cary, NC.

Sebrant, U. (2008), "The impact of emotion and power relations on workplace learning", Studies in the Education of Adults, 40(2): 192-206.

Siegrist, J. (1996), “Adverse health effects of high effort-low reward conditions”, Journal of Occupational Health Psychology, 1: 27-41.

Stansfeld, S. and Candy, B. (2006), "Psychosocial work environment and mental health-a meta-analytic review", Scandinavian Journal of Work, Environment \& Health, 32(6): 443-462.

Stansfeld, S., Shipley, M., Head, J., Fuhrer, R. and Kivimaki, M. (2013), "Work characteristics and personnel social support as determinants of subjective well-being”, PLoS ONE, 8(11): e81115.

Su, J.-A., Weng, H.-H., Tsang, H.-Y. and Wu, J.-L. (2009), "Mental health and quality of life among doctors, nurses and other hospital staff”, Stress and Health, 25: 423-430.

Swedish Research Council, http://www.vr.se/forskning/etik

Theorell, T. (2000), "Job characteristics in a theoretical and practical health context", in Cooper, C.L. (Ed.), Theories of organizational stress. Oxford: Oxford University Press, pp. 205-219.

Undén, A.L. and Orth-Gomér, K. (1989), "Development of a social support instrument for use in population surveys", Social Science and Medicine, 29(12): 1387-1392.

VanVactor, J.D. (2012), “Collaborative leadership model in management of health care", Journal of Business Research, 65: 555-561.

Waris, K. (1999), Mental Well-being at Work. A Sign of a Healthy Organisation and a Necessary Precondition for Organisational Development. Finnish Institute of Occupational Health, People and Work. Research Reports 28, Helsinki.

West, M.A., Borrill, C.S., Dawson, J.F., Scully, J., Carter, M., Anelay, S., Patterson, M. and Waring, J. (2002), "The link between the management of employees and patient mortality in acute hospitals", The International Journal of Human Resource Management, 13(8): 1299-1310. 